\title{
On the Internal Structure of Tashlhiyt Berber Triconsonantal Roots*
}

\begin{abstract}
Mohamed Lahrouchi
This paper examines the internal structure of triconsonantal roots in Tashlhiyt Berber. It is proposed that these roots have a binary-branching head complement structure, built upon the sonorant and the segment immediately to its left. Evidence for this structure is provided by the imperfective formation. It is argued that only roots that display such a structure undergo gemination in the imperfective. This allows us to account for a number of forms that are traditionally ascribed to lexical idiosyncrasy, including verbs that are made entirely of obstruents and those where the only sonorant is in the initial position.
\end{abstract}

Keywords: roots, imperfective, Tashlhiyt Berber, phonology, morphology.

Following the traditional view, the lexicon ${ }^{1}$ of the Afroasiatic languages is mainly made up from triconsonantal roots. ${ }^{2}$ Many of these roots are said to be historically derived from earlier biconsonantal roots (see MacDonald 1966, Diakonoff 1970, Weil 1979, Tobin 1990, Zaborski 1991, and Elmedlaoui 1994) or to contain some specific consonants, which Ibn Jinni (-1002) called "almoutlaqat" in the case of Classical Arabic. Moreover, they obey phonological constraints that limit the kind of segments they contain. Thus, for instance, adjacent gutturals are prohibited in the same root (see Greenberg 1955).

Berber and Semitic, more particularly Classical Arabic, converge on these properties. They however diverge on the nature and the arrangement of segments in the root. Specifically, in Classical Arabic a root may consist entirely of voiceless obstruents (see examples in (1)), whereas in Tashlhiyt Berber each triconsonantal root contains at least one sonorant, most often preceded by an obstruent. $^{4}$

(1) Classical Arabic

$\begin{array}{lll}\sqrt{k \int f} & \text { kafaf } & \text { 'pull away' } \\ \sqrt{k f s} & \text { kafas } & \text { 'be bandy-legged' } \\ \sqrt{ } \text { ksf } & \text { kasaf } & \text { 'be or become dark' }\end{array}$

The analysis will focus on this particular property that differentiates Tashlhiyt Berber and Classical Arabic roots. The aim is to show that many of the verbal triconsonantal roots in Tashlhiyt Berber are basically binary, in that only two of their segments are constrained. In section 1, I give an

\footnotetext{
* Manuscript version, to appear in Linquistic Inquiry 41-2 (2010)
} 
overview of the notion of "root" in Afroasiatic languages as opposed to Indo-European languages. In section 2, I present the relevant Tashlhiyt Berber data. In section 3, I put forward a hypothesis on the internal structure of Tashlhiyt Berber triconsonantal roots. I propose that roots of this kind have a binary-branching head-complement structure built upon the sonorant and the consonant to its left. Biconsonantal roots are examined in section 4 . Evidence for the binary-branching head-complement hypothesis is provided in section 5 by the imperfective formation: it is argued that only verbs that display such a structure geminate a consonant in the imperfective, and the way this gemination is achieved depends on how the root is internally structured. This proposal challenges earlier syllable-based accounts of the phenomenon (see Dell and Elmedlaoui 1988, 2002, Jebbour 1999, and Bensoukas 2001), making the role of the syllable redundant in determining the geminating consonant in the verb.

\section{What is in a Root?}

\subsection{The Segmental Content of the Root}

A recurring question in the Berber derivational morphology relates to the role of the root in word formation processes. Several scholars have challenged the various attempts to define this object: what is a root made of? What is its role in word formation processes?

In Indo-European languages, the root is roughly considered to be the smallest meaningful lexical unit that a set of items share in common. This lexical unit is assumed to contain both consonants and vowels. Thus, for example, the items reason, reasoning, and reasonable share the root reason whereas receive, deceive, perceive, and conceive share the root ceive, which never occurs by itself. ${ }^{5}$ In contrast, in the overwhelming majority of Semitic linguistics, semantically-related words are described as sharing a common root that consists entirely of consonants. Within the autosegmental phonology program, root consonants have acquired a morphological status expressed through multi-tiered representations where the root lies on a distinct tier (see McCarthy 1979, 1981). Associated with vocalic melodies and affixes to specific templates, they form words. ${ }^{6}$ Thus, for example, the Classical Arabic root $\sqrt{ } k t b$ 'write' associated with the vocalic melody $i$ - $a$ to the template CVCVVC derives the form kitaab 'book', which contrasts with the form kaatib 'writer' derived through the association of the same root with the inverse melody $a-i$ to the template CVVCVC. This is shown in (2): 
(2)

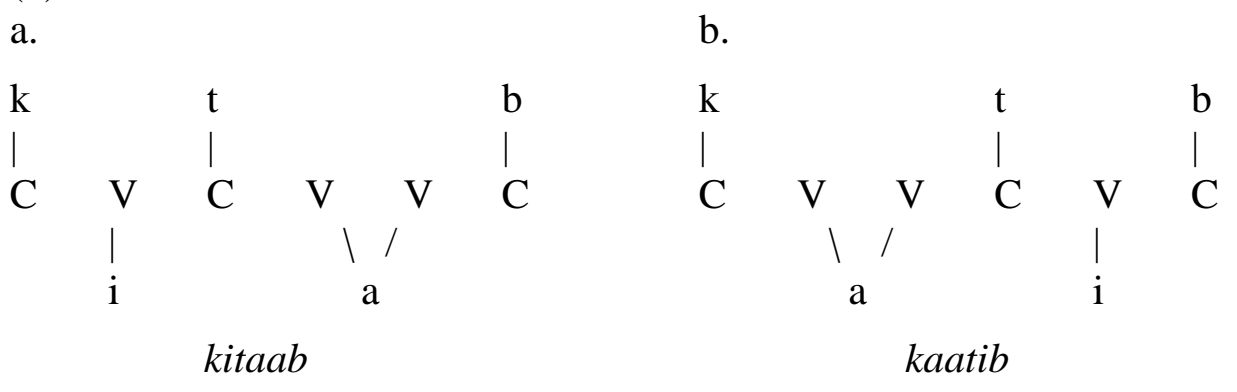

Additional arguments from word games and secret languages support the idea of root consonantism and its relevance in word formation processes. ${ }^{7}$ McCarthy $(1981: 379,1991: 12)$ has, for example, pointed out the ability of word game users to extract and manipulate the consonants that form the root. He has noticed that the basic operation that underlies a Bedouin Hijazi Arabic word game consists in the extraction and the permutation of root consonants. A verbal form such as kuttib 'writecausative-passive-perfective-3ms' is rendered by one of the following disguised forms: buttik, kubbit, tukkib, tubbik, bukkit. External evidence from language disorder and speech errors is provided in Prunet, Béland and Idrissi 2000, and Idrissi, Prunet and Béland 2008. On the basis of errors made by aphasic patients, the authors argue that 'Arabic roots can be accessed as independent morphological units' (2000: 610). They present a case study of a bilingual Arabic-French aphasic patient who produces more metathesis errors in Arabic than in French. The metathesis errors he produces in Arabic consist in modifying the linear order of root consonants: for example, Rih-t-imaal $\rightarrow$ Pih-t-ilaam 'probability', fuqar-aa? $\rightarrow$ furaqaa? 'poor', ma-sba $\rightarrow$ ma- $\hbar b a s$ 'swimming pool'. Further evidence for consonantal root in Semitic is provided in Prunet 2006.

The contrast between Indo-European and Semitic languages with respect to the notion of 'root' conveys the traditional opposition between concatenative and nonconcatenative morphologies. In Berber languages, the issue is not so clear-cut, although most scholars (see among others Basset 1929, Cantineau 1950, Galand 1988, and Chaker 1990) conceive the root as the minimal meaningful unit, entirely composed of discontinuous consonants, ordered in a fixed way and bearing a general meaning, while vowels have a grammatical role. Other scholars working for the most part within the generative tradition (see Moktadir 1989, Dell and Jebbour 1991, Dell and Elmedlaoui 1991 and 1992, and Bensoukas 2001), ${ }^{8}$ on the contrary, claim that in certain cases consonants and vowels should not be separated as they share lexical information (see also Kossman 1997:130). The argument is given with the aorist form, described as an indivisible verbal form in which vowels coexist with consonants (examples follow in 
(3)), as well as with the high vowel/glide alternation analyzed as the phonetic reflex of the same underlying segment.

The ambiguous status of the root in Berber is actually related to the hybrid morphological operations the language uses. That is, the Berber morphology is a mixture of concatenative and nonconcatenative operations. On the one hand, most scholars agree with the fact that words such as $d l$ 'cover!', addal 'chador', taduli 'covering', amdlu 'cloud', and imdl 'cap' share the root $\sqrt{ } d l$. Likewise, askrz 'plow', amkraz 'plowman', and tayrza ( $\leftarrow$ takrza) 'plowing' share the root $\sqrt{ } k r z$. On the other hand, several word formation processes - basically concatenative - are not readily analyzable in terms of a consonantal root. The following verbal forms illustrate the issue:

$\begin{array}{llll}\text { (3) Preterit } & \text { Imperfective } & \text { Aorist } & \\ \text { a. inkr } & \text { nkkr } & \text { nkr } & \text { 'stand up' } \\ \text { izgr } & \text { zggr } & \text { zgr } & \text { 'cross' } \\ \text { ik }{ }^{\mathrm{w}} \text { na } & \text { knnu } & \mathrm{knu} & \text { 'lean' } \\ \text { ibri } & \text { brri } & \text { bri } & \text { 'scratch' } \\ \text { b. imun } & \text { ttmuna } & \text { mun } & \text { 'accompany' } \\ \text { imatr } & \text { ttmatar } & \text { matr } & \text { 'watch, oversee' } \\ \text { isawl } & \text { sawal } & \text { sawl } & \text { 'speak' } \\ \text { iwala } & \text { ttwala } & \text { wala } & \text { 'border on' }\end{array}$

By means of a simple discovery procedure, verbs given in (3a) are decomposable into discrete morphemes linearly concatenated. Preterit forms consist of three consonants preceded by the third person masculine marker $i$ while imperfective forms involve the gemination of the medial consonant. In contrast, aorist forms undergo no morphological operation. They merely exhibit the three consonants common to the other two verbal conjugations. Verbs in (3b) involve both concatenated and nonconcatenated morphemes. Apart from aspect and person markers, the remaining morphemes are problematic in that they are neither divisible into smaller meaningful units nor reducible to consonantal roots. The vowels they exhibit are commonly described as being part of the base. Similarly, certain nouns display indivisible bases while in others root consonants are easily extracted. Singular and plural formations illustrate the problem. Singular forms such as asaru 'pipe', asafu 'torch', and agrtil 'plait' fall readily under the root-andpattern morphology, as they share with their plural counterparts isura, isufa, and igrtal the same consonantal material, while their vowels show regular alternations. ${ }^{9}$ Other nouns, by contrast, keep their internal vowels unchanged and form their plurals merely by means of suffixation: for example, (sg) ikzin $\rightarrow(\mathrm{pl})$ ikzin-n 'pup', ayniw $\rightarrow$ ayniw- $n$ 'palm tree', $\operatorname{argaz} \rightarrow \operatorname{irgaz}-n$ 'man', abid ${ }^{\uparrow}$ ar $\rightarrow$ ibid $^{S}$ ar-n 'lame'.

Nevertheless, one noticeable difference remains between Tashlhiyt Berber and Classical Arabic with respect to root structure. In the first 
language, the consonantal root is surface-true, whereas in Classical Arabic, it is an abstract morpheme that never surfaces as such. Thus, for instance, in Tashlhiyt Berber the consonants $d l$ shared by the items addal, taduli, amdlu, and imdl surface as such in the aorist form of the verb meaning 'cover'. Likewise, the consonants $k r z$ common to the items askrz, amkraz, and tayrza ( $\leftarrow$ takrza) form the aorist of the verb meaning 'plow'. On the contrary, in Classical Arabic the consonants $k t b$ necessarily combine with vocalic morphemes and templates to form words such as kataba 'he wrote', kitaab 'book', and kaatib 'writer'. Yet, some authors such as Hammond (1988), and McCarthy and Prince (1990) reject the consonantal root in Classical Arabic with arguments that such a morpheme involves a high degree of abstraction and fails to account for transfer phenomena as in the singular forms sult 'aan 'sultan', and zund $\underline{u} b$ 'grasshopper', where the length of the second vowel is transferred in the plural forms salaat $\underline{\text { iin }}$ and zanaadib. Similar criticisms are found in Bat-El 1994, 2003, and Ussishkin 1999 in the case of Hebrew.

\subsection{Morphological Productivity and Learnability}

Morphological productivity can be defined informally as the extent to which a given affix or grammatical process is used in the formation of new words. ${ }^{10}$ If consonantal roots exist as such in the lexicon of Tashlhiyt Berber, we expect them to have an active role in word formation. Also, words are expected to be stored once analyzed into a consonantal root plus other grammatical morphemes. This is actually the case in Classical Arabic, where loan words tend to preserve the original consonantal material. Thus, for example, the French words doublage 'doubling', télévision 'television', four I fourneau 'oven, stove', and franciser 'Frenchify' are adapted as dablaza, talfaza, furn, and farnasa, respectively. Likewise, the words nucleus, tomatoes, and dolphin are adapted as nawaat, $t^{\uparrow}$ amaat ${ }^{\uparrow} \mathrm{m}$, and dalfiin. Moreover, many of these words undergo the usual nonconcatenative operations: for example, 'nucleus' nawaat / nawawii 'nuclear', 'dolfin' dalfiin (sg) / dalaafin (pl), 'oven' furn (sg) / afraan (pl). On the contrary, in Tashlhiyt Berber, French words such as gratter 'scrape', changer 'change', entraîner 'train', blesser 'injure', and accélérer 'speed up' are adapted as grate, fange, ttrini, blisi, and ksiri, respectively. Their original consonantal and vocalic material is preserved, with some minor phonological adaptations such as vowel rising $(\mathrm{e} \rightarrow \mathrm{i})$, denasalisation $(\tilde{\mathrm{a}} \rightarrow$ an), and deletion ( $\tilde{\mathrm{a}}$ in entraîner). The same reasoning holds for neologisms that are derived from other words by means of prefixation or suffixation: for example, in the word tasnawalt 'linguistics' we find the word awal 'speech, language'. Similary, the sequence akal 'earth, ground' is found in the word 
tasnakalt 'geography', and the word tasnaddert 'biology' contains adder 'be alive' (see Sagarna 1988, Achab 1996, and Taïfi 1997).

Another question of concern with the structure of the root in Tashlhiyt Berber is learnability. Much work in phonology has been motivated by the problem of how learnable are grammatical systems (see Dresher 1999). Complex and abstract systems are commonly considered as difficult to learn, since they require more decisions from the learner. Some of the authors that reject the consonantal root in Semitic discuss learners' difficulty to use such an abstract morpheme in word formation, whereas fully specified words make the learning process easier (see Bat-El 2003: 45). In Tashlhiyt Berber, plenty of consonantal roots are surface true and hence likely to be learned from direct evidence.

In summary, whether Berber roots are entirely composed of consonants or whether they contain vowels as well as consonants is a complex issue still under debate. In this paper, the focus is on the analysis of triconsonantal verbs that surface with no full vowels and verbs with the following shapes: CCI and CCU.

\section{Data}

For the purposes of the analysis, a list of 222 native verbs ${ }^{11}$ (given in the appendix) was collated from various sources including Dell and Elmedlaoui 1988, 2002, Boumalk 2003, and El Mountassir 2003. The list contains 122 triconsonantal verbs with no full vowels, 74 verbs with CCI and CCU shapes, and 26 biconsonantal verbs. They are sorted into different classes with respect to the kind of consonants they contain. The examination of the data shows that verbal triconsonantal roots in Tashlhiyt Berber obey a set of phonological constraints that limit the nature of the segments they contain. ${ }^{12}$ Consider the examples in (4). They are sorted into four classes labeled OOS, OSO, SOS, and OSS, where O stands for an obstruent and $\mathrm{S}$ for a sonorant. $73 \%$ of the roots listed in the appendix belong to these classes.

(4)

$\begin{array}{ll}\text { a. OOS } & \\ \text { gzm } & \text { 'cut' } \\ \mathrm{k} \int \mathrm{m} & \text { 'enter' } \\ \mathrm{bsr} & \text { 'spread out' } \\ \mathrm{zgr} & \text { 'cross' } \\ \mathrm{bdr} & \text { 'mention, } \\ \text { b. OSO } & \\ \text { frd } & \text { 'nibble' } \\ \mathrm{krz} & \text { 'plough' } \\ \mathrm{krf} & \text { 'tie up' } \\ \text { xrb } & \text { 'scratch' }\end{array}$




$\begin{array}{ll}\text { smd } & \text { 'add' } \\ \text { c. SOS } & \\ \text { ndr } & \text { 'squirt' } \\ \mathrm{mgr} & \text { 'reap' } \\ \mathrm{lkm} & \text { 'arrive' } \\ \mathrm{nkr} & \text { 'stand up' } \\ \mathrm{rgl} & \text { 'knock' } \\ & \\ \text { d. OSS } & \\ \mathrm{knu} & \text { 'lean' } \\ \text { 3lu } & \text { 'loose' } \\ \text { bri } & \text { 'scratch' } \\ \mathrm{xmr} & \text { 'ferment' } \\ \mathrm{yml} & \text { 'mould' }\end{array}$

The constraints are listed in (5):

(i) Each root contains at least one sonorant. $94 \%$ of the roots listed in the data obey this constraint. Counterexamples involve roots such as $b d g$ 'be wet', $b z g$ 'swell', and $z d \gamma$ 'inhabit'. ${ }^{13}$

(ii) A root may contain at most two sonorants, as in the examples given in (4c) and (4d). Counterexamples such as $r m i$ 'be tired', rwi 'make dirty', and $m l u$ 'be limp' do not exceed $9 \%$ of the data.

(iii) At least one sonorant of each root is preceded by an obstruent. $82 \%$ of the data obey this constraint.

(iv) The sonorant can appear in the final position of the root (4a) as well as in the medial position (4b).

(v) If a root begins with a sonorant, it also ends with a sonorant (4c). 16 triconsonantal roots contradict this statement (see classes 5 and 6 in the appendix).

(vi) If two sonorants are adjacent in the root, then the second sonorant is more sonorous $(4 \mathrm{~d})$, (the pattern is most often of the form [liquid + high vocoid] or [nasal + high vocoid]). 8 Counterexamples to this constraint are found in the data;

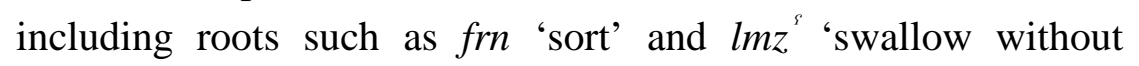
chewing' (see classes 4 and 5 in the appendix).

In sum, the sonorant can appear in any position: root-final as in $\mathrm{gzm}$ 'cut', root-medial as in frd 'nibble' or root-initial as in $n g s$ 'jostle'. The table below in (6) summarizes the main constraints stated in (5): 


\begin{tabular}{lccc}
\hline & \multicolumn{2}{c}{ True for } & Exceptions \\
& Number of items & Percentage & Percentage \\
\hline At least one $S$ & 185 & 94.38 & 5.61 \\
At most two S & 178 & 90.82 & 9.18 \\
At least one S preceded by O & 161 & 82.14 & 17.86 \\
If a root begins with S it also & 44 & 72.13 & 27.87
\end{tabular}

ends with $\mathrm{S}$

As far as I am aware, such constraints on the segmental composition of triconsonantal roots in Tashlhiyt Berber have not been documented elsewhere. However, Elmedlaoui (1994) suggests, following Ibn Jinni (d. 1002), and Diakonoff $(1970,1988)$, that in Afroasiatic the sonorants $m, l$, and $r$ are historical affixes. He gives the following examples:

(7)

$\begin{array}{llll}\begin{array}{l}\text { Root } \\ \sqrt{\text { gz }}\end{array} & \text { Tashlhiyt Berber } & \text { Classical Arabic } & \text { Hebrew } \\ & \text { gzm 'to cut' } & \begin{array}{l}\text { gazam 'to cut' } \\ \text { gazar 'to prune' }\end{array} & \begin{array}{l}\text { gazam 'to pazane' } \\ \text { gazar 'to cut' }\end{array} \\ \sqrt{\text { qd }} & & \text { qardam 'to cut' } & \text { qardum 'axe' }\end{array}$

He proposes that the sonorants are used to extend roots. Further examples are given with Berber onomatopoeia:

(8)

Onomatopoeia onomatopoeia intensified onomatopoeia super-intensified

ttaqq ttraqq trtllaqq

bbaqq bbraqq brbllaqq

ddaxx ddraxx drdllaxx

These onomatopoeic forms that commonly mimic friction, explosion and shock use sonorants to express intensity or reinforcement.

The following section develops the hypothesis that Tashlhiyt Berber triconsonantal roots are basically binary, in that only two of their segments are constrained. Section 5 shows that certain morphological operations are sensitive to the segmental composition of the root.

\section{The Internal Structure of the Verbal Triconsonantal Roots}

\subsection{A Binary-Branching Head-Complement Structure}

The main idea that emerges from the data discussed in the previous section is that the segmental composition of the verbal triconsonantal roots in Tashlhiyt Berber obeys structural and distributional constraints, in the forefront of which is the following constraint:

(9) In Tashlhiyt Berber, each verbal triconsonantal root contains at least one sonorant.

In addition, root consonants undergo cooccurrence restrictions that are captured in terms of sonority-sensitive dependency relationships 
between the most sonorous segment in the root and the neighboring segments. ${ }^{14}$ Indeed, we notice that a sonorant is often preceded by an obstruent. Moreover, if two sonorants are contiguous, then the second sonorant is necessarily more sonorous, the typical case being a liquid or a nasal followed by a high vocoid (see class 4 in the appendix).

All of these structural and distributional constraints suggest a specific internal organization of the root. The question is then how to state a conceptual framework that accounts for this internal organization, on the one hand, and the cooccurrence restrictions the root consonants undergo, on the other hand. We need to specify the status of the sonorant and the obstruent in the root, and capture the distributional constraints they undergo.

I propose that Tashlhiyt Berber triconsonantal roots are internally structured in such a way that only two of their segments are constrained, namely the sonorant and the consonant immediately to its left. ${ }^{15}$ More particularly,

(10) Verbal triconsonantal roots display a binary branching headcomplement structure. ${ }^{16}$

This structure is hierarchical, rendered by means of a tree diagram analogous to those that represent syllabic and syntactic constituencies. The segments that act as the head and the complement share the same node in the tree. The remaining segment - linked to a higher node in the tree - is a satellite that occurs indifferently to the left or the right of the headcomplement pair (examples follow in 12). In addition, the head and the complement are constrained as follows:

a. The head is located immediately on the left of the most sonorant segment.

b. An obstruent never occurs as the complement.

These constraints imply that the head segment can be initial as in frd 'nibble' or medial as in $g z m$ 'cut', but not final. To illustrate the theoretical devices stated in (10) and (11), some of the roots given in (4) are represented below (the head position is indicated by the dot at the end of the branch):
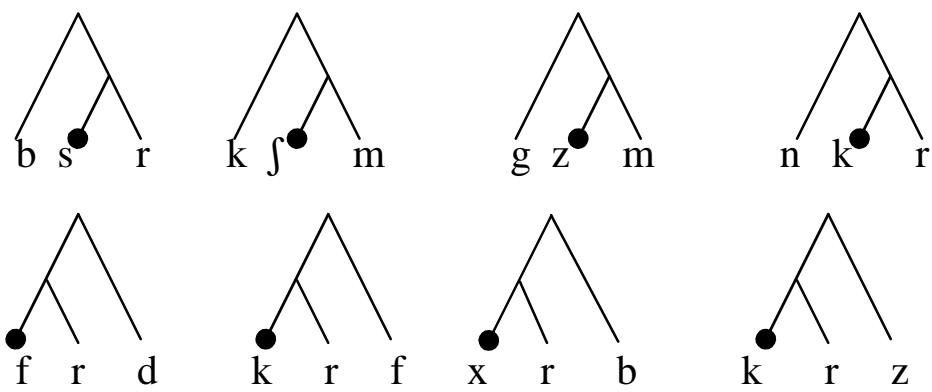
In these examples, the head and its complement obey the constraints stated in (11):

(i) The head accommodates the obstruent located immediately on the left of the sonorant ( $s$ in $b s r, \int$ in $k \int m, z$ in $g z m$, etc.).

(ii) The head is initial or medial, but not final.

(iii) No obstruent appears in the complement position.

Before examining the structure of the remaining roots in (4), namely those of the form OSS, let us consider some aspects of the hierarchical structures displayed in (12). What is at stake is the motivation of the head and complement constituency, and its relevance in accounting for the cooccurrence restrictions that the roots undergo. Particularly, we want to know why the obstruent is assigned the head function. The following section provides some answers to these questions.

\subsection{Headedness Function}

It is generally assumed that headedness is an essential function and that each grammatical constituent must be headed. It is also assumed that certain elements display particular properties that allow them to act as heads. In syllabic structures, for instance, the nucleus is assumed to be the head of the syllable, essentially because it is the only obligatory constituent. A syllable may indeed be onset-less, coda-less or both, but it must have a nucleus. That is to say, it must be headed. ${ }^{17}$ Similarly, in syntactic constituencies, heads are most often the obligatory elements, as opposed to complements, which are optional. For instance, the verb is assigned the head function in part because it can form a verb phrase by itself.

Within root structure, we expect head elements behave similarly to their counterparts in syntactic and syllabic structures. That is, we expect the obstruents that function as heads to be able to occur without their complement (i.e. sonorants), just as syllabic and syntactic heads do sometimes occur without their complement. If there were any monoconsonantal words in Tashlhiyt Berber, their roots should be made exclusively of obstruents. This is actually the case; the very few monoconsonantal roots that Tashlhiyt Berber contains are all made of obstruents: for example, $k k$ 'pass', $g$ 'be', $\iint$ 'eat', and $f$ 'give'. Obstruents and sonorants are undeniably essential for roots to be well-structured; most often they cooccur in bi- and triconsonantal roots, but only obstruents occur in monoconsonantal roots. ${ }^{18}$

\subsection{Head-Sonorant Roots}

A sonorant occurs in the head position when it is followed by a more sonorant segment as in the examples represented below: 

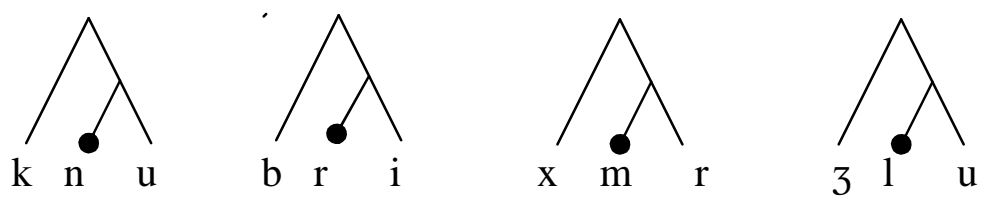

Roots of the form OSS are commonly found in Tashlhiyt Berber ( $21 \%$ of the triconsonantal roots in the appendix are of this type). Most of them end with a high vocoid. Their head is assigned to the medial sonorant by virtue of (11a). The roots that end with a nasal plus a liquid also assign the head function to the medial consonant $\left(x m r, f m l, g^{w} m r\right.$, and $\hbar m l$ are the only examples found in class 4 in the appendix), while those that end with a liquid plus a nasal such as $\mathrm{krm}$ and $\mathrm{frn}$ assign the head function to the initial segment ( 7 roots in class 4 are of this type).

Roots of the form SSS (the data in the appendix contain 7 roots of this type) all assign the head function to the medial sonorant, except $r w l$ 'run away' whose head is in the initial position.

\subsection{Left-Headed Structures}

The examples represented in (12) and (13) show that any verbal triconsonantal root in Tashlhiyt Berber is basically binary, ${ }^{19}$ in that only the head and its complement are constrained. Their binary branching structure locally determines their cooccurrence restrictions. Indeed, the phonological constraints they obey are limited to the inferior node in the tree. As a consequence of this binary structure, the remaining position in the root, namely the one that is linked to the superior node in the tree, is free to accommodate any kind of segment, obstruents (e.g., $b$ in $b s r$ ) as well as sonorants (e.g., $n$ in $n k r$ ). It also acts as a satellite of the head and the complement pair, as it occurs at the far left or the far right of the tree. In addition, the careful reader will have noticed that an important property emerges from the tree-based structures given in (12) and (13): the head is systematically located on the left branch of the inferior node in the tree.

This is a notable outcome of the analysis; comparable to similar proposals for syntactic structures (see the Linear Correspondence Axiom proposed by Kayne (1994)). ${ }^{20}$

\subsection{Problematic Data}

Data that contradict the constraints in (10) and (11) are sorted into two types:

(i) Roots in which the only sonorant is initial as in $n g s$ 'jostle, shove', $r k z$ 'dance', and $n f d$ 'be stirred up' (13 roots in the data in the appendix are of this type, see class 6).

(ii) Sonorant-less roots such as $b d g$ 'be wet', bzg 'swell', and bxs 'discredit oneself' (the data contain 16 roots of this type, of which 
11 are triconsonantal and 5 biconsonantal see classes 8 and 12 in the appendix).

Both types are problematic with respect to the constraints in (11): the first are able to assign their head neither to the initial nor to the medial consonant, as their only sonorant appears in the initial position. The latter are not decomposable into a binary branching head-complement structure, since we would need to determine which segments among the three sonority-equal radicals are the head and the complement. The example represented in (14) illustrates the problem:

a.

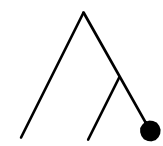

b $\quad$ d $\quad g$

d.

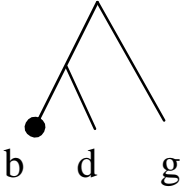

b.

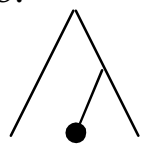

b $\quad d \quad g$

e.

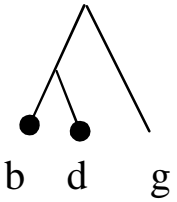

c.

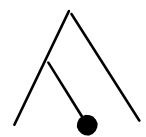

b $\quad$ d $\quad$ g

f.

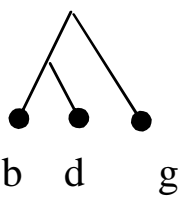

The structures in (14a) and (14c) are prohibited by virtue of the assumption that the head always precedes its complement. Those in (14b) and (14d) are problematic as nothing in the analysis allows $b$ and $d$ sonority-equal segments - to be the head and the complement. The remaining structures in (14e) and (14f) are ill-formed because they are multi-headed.

We will return to these examples in section 5.3. We now examine the internal structure of biconsonantal roots. These roots will prove crucial to the analysis, as we expect them to be composed of a head and its complement.

\section{Biconsonantal Roots}

The way we have accounted for the internal structure of triconsonantal roots inevitably leads us to the examination of the structure of biconsonantal roots. Indeed, as we have proposed that triconsonantal roots display a binary-branching head-complement structure built upon the sonorant and the consonant immediately to its left; the remaining segment being a satellite, we expect biconsonantal roots to be but triconsonantal minus the satellite segment. That is, we expect them to contain nothing but the head and its complement.

The data given in the appendix contain 26 biconsonantal roots, of which 13 are of the form obstruent-sonorant, 6 of the form sonorant- 
obstruent, 2 obstruent-less and 5 sonorant-less. Let us examine first the behavior of OS roots, which represent $50 \%$ of the biconsonantal roots listed in the appendix. Examples are given in (15) with the aorist, imperfective, and preterit conjugations:

(15) Aorist

Imperfective

\begin{tabular}{|c|c|c|}
\hline \multicolumn{2}{|c|}{ Preterit } & \\
\hline $3 \mathrm{pms}$ & $1 \mathrm{ps}$ & \\
\hline$\sigma \mathrm{n}$ & gn-y & 'sleep' \\
\hline 1 & fl- $\gamma$ & 'leave, let' \\
\hline & $d^{\mathrm{Q}} \mathrm{r}-\mathrm{\gamma}$ & 'fall' \\
\hline & gl-y & 'bust' \\
\hline
\end{tabular}

Roots of this type readily fall in with the binary-branching headcomplement analysis. Their head is assigned to the obstruent; the sonorant being its complement. In $g n$, for instance, $g$ is the head and $n$ its complement. Likewise, in $f l$ the initial consonant is the head and the second one is the complement. In addition, the morphological properties that their verbal forms show in the imperfective and preterit conjugations support the idea that they are true biconsonantal, opposed to the verbs of the form SO which seem to be underlyingly more complex. The examples in (16) illustrate the behavior of the latter:

\begin{tabular}{|c|c|c|c|c|}
\hline (16) Aorist & Imperfective & \multicolumn{2}{|c|}{ Preterit } & \\
\hline & & $3 \mathrm{pms}$ & $1 \mathrm{ps}$ & \\
\hline$a$. & lssa & lsa & $1 s i-y$ & 'wear' \\
\hline $\mathrm{ns}$ & nssa & nsa & $n s i-y$ & 'overnight' \\
\hline $\mathrm{rz}^{\mathrm{q}}$ & $\operatorname{rzz}^{\complement} \mathrm{a}$ & $\mathrm{rz}^{\complement} \mathrm{a}$ & $\mathrm{rzi}^{\mathrm{f}}-\mathrm{\gamma}$ & 'break' \\
\hline $\mathrm{nz}$ & nzza & nza & $n z i-y$ & 'be sold' \\
\hline knu & knnu & $\mathrm{k}^{\mathrm{w}} \mathrm{na}$ & $k^{\mathrm{W}} n i-\mathrm{\gamma}$ & 'lean' \\
\hline $\mathrm{rku}$ & rkku & rka & rki-y & 'be dirty’ \\
\hline 3lu & 3llu & 3la & $3 l i-y$ & 'loose' \\
\hline gnu & gnnu & $\mathrm{g}^{\mathrm{w}} \mathrm{na}$ & $g^{\mathrm{w}} n i-\mathrm{\gamma}$ & ‘sew' \\
\hline
\end{tabular}

The verbs in (16a) behave similar to CCU verbs in (16b), in that they geminate the medial consonant in the imperfective, and use the vowels $a$ and $i$ in the preterit third person masculine singular and first person singular respectively ( $-\gamma$ being the 1 ps morpheme marker). In contrast, the verbs in (15) form their imperfective by geminating the initial consonant and infixing the vowel $a$, while their preterit merely exhibits the two radicals.

On the basis of these similarities, Iazzi (1992) has suggested that verbs as in (16a) contain an underlying vocalic segment that has no more than one distinctive feature, namely [+vocalic]. According to Iazzi, this underlying vowel stands for an ancient segment that went out of use, revealing a state of the language where a vowel, probably $u$, occupied the 
final position of the verb. Certain Berber varieties still use the vowel $u$ in the preterit 3pms: for example, i-nsu 'overnight' in Snous, Menacer, and Ouargla varieties, $i$-lsu 'wear' in Ghadames variety, $i-r z^{\uparrow} u$ 'break' in Seghroushen, Snous, Menacer, Ouargla, and Ghadames varieties, and $i-n z u$ 'be sold' in Menacer and Ouargla varieties (see Basset, edition 2004: 64),.

Following Iazzi's proposal, and based on the morphophonological similarities mentioned above, ${ }^{21} \mathrm{I}$ assume that verbs as in (16a) are underlyingly trisegmental, of the form SOU. This allows them to fall in line with the analysis of SOS roots; their head and complement being assigned to the last two segments, while the initial consonant stands for a satellite segment. Some examples, represented in (17), illustrate the proposal:
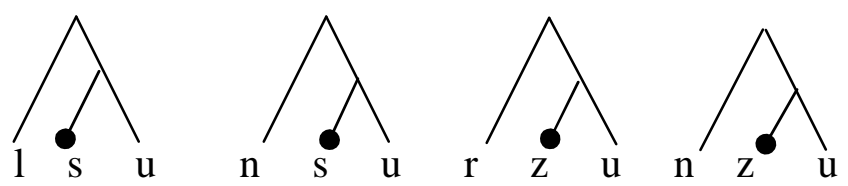

Sonorant-less roots such as $k s$ and $z d^{S}$ are sorted into two groups with respect to the morphophonological properties that their verbal forms display. The data in the appendix contain only five roots of this type. They are listed below in (18):

\begin{tabular}{|c|c|c|c|c|}
\hline (18) Aorist & Imperfective & & & \\
\hline $\mathrm{zd}^{\mathrm{S}}$ & $\operatorname{zzad}^{\text {S }}$ & $\begin{array}{l}3 \mathrm{pms}^{\mathrm{S}} \\
\mathrm{zd}^{\mathrm{a}} \mathrm{a}\end{array}$ & 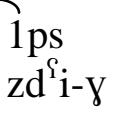 & 'mill, grind' \\
\hline sy & ssay & sya & syi-y & 'buy' \\
\hline$y z$ & qqaz & yza & $y z i-y$ & 'hollow' \\
\hline ks & kssa & ksa & ksi-y & 'graze' \\
\hline $\mathrm{fk}$ & akka & fka & fki-y & 'give' \\
\hline
\end{tabular}

The verbs in (18a) behave completely paradoxically in the morphological properties they display: they share similarities both with verbs of the form SO like $l s$ 'wear' and with those of the form OS like $f l$ 'leave'. On the one hand, their preterit 3pms and 1ps use the vowels $a$ and $i$ respectively, the same as SO verbs. On the other hand, they geminate the initial consonant and infix the vowel $a$ between the two radicals, the same as OS verbs. In contrast, the verbs in (18b) geminate the second consonant and add the vowel $a$ in the imperfective, and use the vowels $a$ and $i$ in the preterit $3 \mathrm{pms}$ and $1 \mathrm{ps}$ respectively, the same as CCU verbs. Hence, the root structure of the verbs in (18b) is taken to be of the form OOU, where the last two segments stand for the head and the complement, similar to that of the verbs in (16a). The structure of the verbs in (18a) remains problematic. 
Their form in the preterit, particularly the fact that they use the vowel $a$ in the 3 pms, and the vowel $i$ in the 1 ps, suggests that they are underlyingly trisegmental, containing the vocoid $U$ in the third position. Their form in the imperfective, in turn, indicates that they are merely biconsonantal.

The remaining biconsonantal verbs in the data, $m l$ 'show' and $n u$ 'be cooked', are of the form SS (see class 11 in the appendix). On the basis of the constraint in (11a), they are assigned a binary-branching structure where the initial sonorant is the head and the second one its complement.

The next section examines one of the most productive morphological mechanisms in Tashlhiyt Berber verb conjugation, namely gemination in the imperfective. It is shown that the binary branching head-complement hypothesis plays a central role in the derivation of the imperfective, determining on the one hand the class of verbs that undergo gemination and on the other hand the segment that geminates in the verb.

\section{Geminated Imperfective}

As a process used to form the imperfective, gemination concerns verbs containing no more than three consonants, without initial or medial vocoids. It has been treated in several studies, including Chaker 1973, 1984, Chami 1979, Boukous 1987, Cadi 1987, Dell and Elmedlaoui 1988, 1991, 2002, Jebbour 1996, 1999, Bensoukas 2001, Lahrouchi 2001, and Louali and Philipson 2004. Dell and Elmedlaoui's account, probably the most influential, rests entirely on syllabic arguments. The authors present the process as evidence in favor of their syllabic algorithm (Dell and Elmedlaoui 1985). In this section, I first discuss Dell and Elmedlaoui's account. Then, I adduce arguments for the relevance of root structure in accounting for this formation. We shall see that gemination as an imperfectivizing mechanism is sensitive to the internal organization of segments in the root: all and only verbs that contain at least one sonorant in a non-initial position, and hence are analyzable into a binary-branching head-complement structure, undergo gemination in the imperfective.

\subsection{Geminate the Onset (Dell and Elmedlaoui 1988, 1991, 2002)}

Dell and Elmedlaoui's syllabic account of gemination in the imperfective is based on the assumption that "the segment which is geminated in the imperfective stem is that segment which is syllabified as an onset by Core Syllabification in the basic stem" (1988: 11). The following examples borrowed from Dell and Elmedlaoui (2002: 118) - illustrate the hypothesis:

\begin{tabular}{|c|c|c|c|}
\hline (19) & Preterit & Imperfective & \\
\hline & krzz & kkrz & 'plough' \\
\hline & Xng & xxng & 'strangle' \\
\hline & $\mathrm{mrz}$ & $\mathrm{mmrz}$ & 'wound in the head' \\
\hline & 3.b $\underline{\mathrm{d}}$ & $3 b^{b d} d^{22}$ & 'draw' \\
\hline & $\underline{\text { r.ks }}$ & rkks & 'hide' \\
\hline
\end{tabular}


$\underline{x}$.si $\quad$ xssi 'extinguish'

The underlined segments in the first column mark syllable nuclei. The period indicates the syllable boundary. In the first three verbs, it is the first consonant that is the onset, while in the other three it is the second consonant. Accordingly, in the imperfective the first three verbs geminate the initial consonant and the second three verbs geminate the medial consonant.

Dell and Elmedlaoui's analysis relies entirely on the information provided by their syllabification algorithm. This algorithm states that in Imdlawn Tashlhiyt Berber any segment can act as a syllable nucleus if it is the most sonorous segment in the syllabification domain: ${ }^{23}$ for instance, $n$ is the syllable nucleus in $x n g$ because it is more sonorous than $x$ and $g$. In $r k s$, $r$ stands for the nucleus of the first syllable, while the remaining segments form another syllable where $s$ is the nucleus and $k$ the onset.

Their analysis of geminated imperfective accounts for almost all of the data. This is not surprising, as the overwhelming majority of triconsonantal verbs contain at least one sonorant, which most often is the nucleus ( $94 \%$ of the roots in the appendix display this property). The issue is quite different when one considers that the presence of sonorants in the root is not a coincidence; they have an essential function, and all and only verbs that have at least one sonorant in a non-initial position form their imperfective by means of gemination. Within Dell and Elmedlaoui's syllabic algorithm where all consonants, including obstruents, may occur as nuclei, we expect that any verb that meets the conditions listed in Dell and Elmedlaoui 1988:11 ${ }^{24}$ automatically undergoes gemination, regardless of the nature of the consonant that occurs in its onset position. To be more specific, we expect sonorant-less verbs to form their imperfective by means of the same process as verbs that contain sonorants. But according to Dell and Elmedlaoui (1988:11), "not all geminable verbs resort to gemination in the imperfective but most of them do" and "the distribution of the geminating verbs among the geminable verbs seems to be a matter of lexical idiosyncrasy". As they do not find geminating verbs entirely made of obstruents, they come to give hypothetical examples to illustrate the predictions of their hypothesis. They suppose that the verbs $* b x s,{ }^{*} z \gamma k$, and *sxf, if they were attested in Imdlawn Tashlhiyt Berber, would form their imperfective by geminating their initial consonant, leading to *bbxs, ${ }^{*} z z d$, and $*_{s s x f}$, respectively. ${ }^{25}$ The so-called hypothetical verbs entirely made of obstruents do actually exist in Tashlhiyt Berber: for example, $k^{w} f s$ 'sow', $b z d^{\complement}$ 'urinate', $b z g$ 'swell', and $b d g$ 'be wet' (further examples are given in class 8 in the appendix). Their imperfective forms are not $* k k^{w} f s,{ }^{*} b b z d^{q}$, $* b b z g$, and *bbdg, as Dell and Elmedlaoui's analysis predicts, but rather $t t k^{w} f a s, t t b z d^{\uparrow} a d^{\uparrow}, t t b z a g$, and $t$ tbdag. ${ }^{26}$ In addition to verbs of this kind, there are verbs in which the only sonorant is initial, such as in $r k z$ 'dance', $n g s$ 
'jostle, shove', rqs 'jump', and $n y d$ 'refine' (see class $\mathrm{n}^{\circ} 6$ for further examples). Within Dell and Elmedlaoui's syllabic algorithm, these verbs are syllabified as follows: $\underline{r} . k \underline{z}, \underline{n} . g \underline{s}, \underline{r} . q \underline{s}$, and $\underline{n} . \underline{y} \underline{d}$ (syllable nuclei are underlined). To form their imperfective, they should geminate the medial consonant that occurs in the onset, leading to *rkkz, *nggs, *rqqs, and $*_{n y y d}$. Again, the imperfective forms of these verbs, at least in those varieties of Tashlhiyt Berber that are described in Boumalk 2003, El Mountassir 2003, as well as in my own variety, use the prefix $t t$ - and the infix $-a$ - instead of geminating the medial consonant.

In summary, Dell and Elmedlaoui's syllable-based analysis fails to capture the reason why only verbs that contain at least one sonorant in a non-initial position undergo gemination. Their analysis does not explain why sonorant-less verbs such as $k^{w} f s, b z g$, and $b z d^{f}$, and verbs in which the only sonorant is initial, form their imperfective by means of affixation rather than gemination. In the next section, I argue that the distribution of the geminating verbs among the geminable verbs is a matter of root structure rather than lexical idiosyncrasy; the presence of at least one sonorant in the root determines the process that the verb undergoes in the imperfective.

\subsection{Geminate the Head}

Below in (20) are repeated the examples given previously in (4), accompanied by their imperfective forms:

(20)

$\sqrt{ } \quad$ Imperfective

$\begin{array}{lll}\text { a. OOS } & & \\ \mathrm{gzm} & \mathrm{gzzm} & \text { 'cut' } \\ \mathrm{k} \int \mathrm{m} & \mathrm{k} \iint \mathrm{m} & \text { 'enter' } \\ \mathrm{bsr} & \mathrm{bssr} & \text { 'spread out' } \\ \mathrm{zgr} & \mathrm{zggr} & \text { 'cross' } \\ \mathrm{bdr} & \mathrm{bddr} & \text { 'mention, evoke' } \\ \mathrm{b} \text {. OSO } & & \\ \mathrm{frd} & \mathrm{ffrd} & \text { 'nibble' } \\ \mathrm{krz} & \mathrm{kkrz} & \text { 'plough' } \\ \mathrm{krf} & \mathrm{kkrf} & \text { 'tie up' } \\ \mathrm{xrb} & \mathrm{xxrb} & \text { 'scratch' } \\ \mathrm{smd} & \mathrm{ssmd} & \text { 'add' } \\ \mathrm{c} . \text { SOS } & & \\ \mathrm{ndr} & \mathrm{nttr} & \text { 'squirt' } \\ \mathrm{mgr} & \mathrm{mggr} & \text { 'reap' } \\ \mathrm{lkm} & 1 \mathrm{kkm} & \text { 'arrive' } \\ \mathrm{nkr} & \mathrm{nkkr} & \text { 'stand up' } \\ \mathrm{rgl} & \mathrm{rggl} & \text { 'knock' }\end{array}$


d. OSS

$\begin{array}{lll}\text { knu } & \text { knnu } & \text { 'tilt' } \\ \text { 3lu } & \text { 3llu } & \text { 'loose' } \\ \text { bri } & \text { brri } & \text { 'scratch' } \\ \text { xmr } & \text { xmmr } & \text { 'ferment' } \\ \text { yml } & \text { ymml } & \text { 'mould' }\end{array}$

An examination of these examples shows that:

(i) each verb geminates one consonant in the imperfective,

(ii) the geminated consonant varies from one category of verbs to the other: the verbs in (20b) geminate the first consonant while the remaining geminate the second consonant,

(iii) gemination never involves the third root consonant,

(iv) a sonorant never geminates in the imperfective except when immediately followed by another sonorant as in the examples in (20d).

Among all Berber varieties, Tashlhiyt is the only variety where gemination in the imperfective is unstable: it involves the initial or the medial segment in the root. The challenge is then to explain how the geminated segment is determined. A further look at the verbs in (20), and more particularly the root structure they display, leads to the following generalization:

(21) The segment which is geminated in the imperfective is that segment which appears in the head position of the root.

Thereafter, the difference between verbs that geminate the initial consonant and those that geminate the medial consonant lies in that the first are head-initial and the second head-medial. That is, the verbs in (20b) display the structure $((\underline{\mathrm{x}} \mathrm{x}) \mathrm{x})$, and the remaining the structure $(\mathrm{x}(\underline{\mathrm{x}} \mathrm{x}))$; the underlined segment being the head and the segment to its right the complement.

Biconsonantal verbs of the form OS, SO, and $\mathrm{OO}$ also obey the rule in (21). The first geminates the initial consonant as it is in the head position (e.g., gn $\rightarrow$ ggan). The remaining, analyzed as underlying trisegmental of the form SOU or OOU, geminate as expected the medial consonant.

So far, our analysis makes the same predictions as syllable-based analyses. This is not surprising since the verbs examined so far in this section all contain at least one sonorant in a non-initial position. The difference between the present approach and the syllable-based approaches arises in the analysis of verbs such as $b d g$ 'be wet' and $r k z$ 'dance', which syllable-based approaches count as regular verbs that should undergo gemination. We will see in the following section that the behavior of these verbs in the imperfective, particularly the fact that they do not undergo gemination, is a matter of root structure rather than lexical idiosyncrasy. 


\subsection{Nongeminating Verbs}

Part of the so-called 'nongeminating verbs' form their imperfective by means of $t t$ - prefixation and $-a$ - infixation, rather than by gemination. Examples are given in (22):

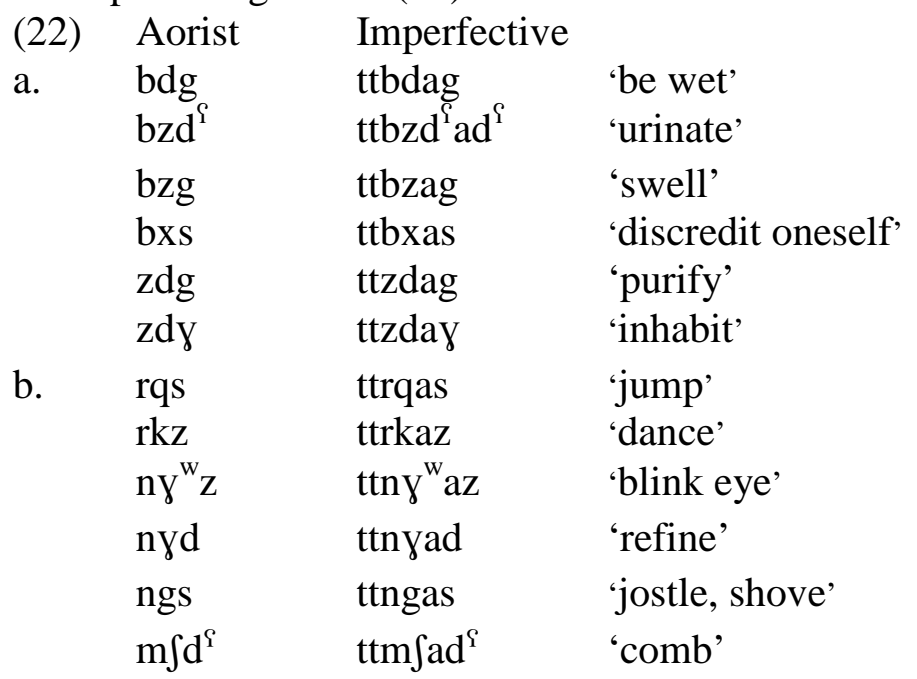

Verbs in (22a) are entirely made of obstruents, and those in (22b) have their only sonorant in the initial position. At first sight, it is puzzling why such verbs do not undergo gemination in the imperfective. Within Dell and Elmedlaoui's syllable-based analysis, these verbs should have geminated the initial or medial consonant, depending on which one appears in the onset position. For instance, the verb bzg should have formed its imperfective as *bbzg, while $r k z$ should have led to * $r k k z$, according to Dell and Elmedlaoui $(1988,2002)$. But, if we look carefully at these verbs' segmental composition, and if we accept the view that for any verbal root to undergo gemination, it must be internally structured according to the proposed analysis, then we understand why the above verbs behave differently. Since the verbs in (22) are not analyzable into a binarybranching head-complement structure, similar to that of the verbs that contain at least one sonorant in a non-initial position, they do not undergo gemination in the imperfective.

However, a few exceptions remain. The verbs $n f f$ 'scrape', $n s d^{\wp}$ 'gush', lqz 'crush', and $l b Z^{\uparrow}$ 'squash' display the same segmental composition as the verbs in (22b). Nevertheless, they undergo gemination in the imperfective leading to $n \int f f$, $n s d^{\S}$, $1 q q 3$, and $1 b b 3^{\S}$ respectively. Similarly, the verbs $b k s$ 'fasten', st $y$ 'split', and $f t k$ 'sprain' form their imperfective by means of gemination, though they are entirely made of obstruents.

Finally, a word must be said about verbs that begin with a sibilant. In regard to their segmental makeup they should undergo gemination in the 
imperfective. Thus, for instance, verbs such as $s k r$ 'do', sgl 'bury', stl 'weigh', sty 'crack, fissure', sli 'touch', and sxn 'dip, dunk' should geminate their medial consonant, as it should be in the head position. Rather, they form their imperfective by infixing the vowel $a$ between the last two consonants. This is apparently due to the fact that Tashlhiyt Berber speakers analyze these verbs as if they were derived forms, divisible into a causative morpheme $s$ - plus a verbal root. It is indeed a known fact that the causative forms do not undergo gemination in the imperfective. Rather, they systematically use the infix $-a-$ : for example, 'arrive' $l \mathrm{~km}$ (aorist) $\rightarrow l \mathrm{kkm}$ (imperfective) / sslkm (causative aorist) $\rightarrow$ sslkam (causative imperfective); 'lean' knu (aorist) $\rightarrow$ knnu (imperfective) / ssknu (causative aorist) $\rightarrow$ ssknaw (causative imperfective); 'sleep' gn (aorist) $\rightarrow$ ggan (imperfective) / $s g n$ (causative aorist) $\rightarrow$ sgan (causative imperfective).

Nongeminating verbs also include borrowed verbs, mainly from Arabic. They form their imperfective by means of $t t$ - prefixation rather by gemination. For example, the verbs $x d m$ 'work', $f t l$ 'enrol (cigarette)', $\hbar k m$ 'judge' and $n z^{m}$ 'escape' form their imperfective as ttxdam, ttftal, tthkam, and ttnzam, and not *xddm, ${ }^{*} f t t l, * \hbar k k m$, and $* n z z m$.

\subsection{Summary of the Analysis of Geminated Imperfective}

Among the verbs that resist syllable-based analyses of gemination in the imperfective are those that are made entirely of obstruents and those where the only sonorant is in the initial position. Based only on syllable judgement, verbs such as bzg 'inflate' and $r k z$ 'dance' should form their imperfective as *bbzg and *rkkz. The analysis advocated here tackles the problem in terms of root rather than syllable structure. It is proposed that only roots that contain at least one sonorant in a non-initial position, and hence are analyzable into a head-complement structure, in line with the proposal made in section 3, undergo gemination in the imperfective. Moreover, the decision as to which consonant geminates depends on where the head is located: head-initial roots such as $f r d$ 'nibble' geminate the initial consonant, and head-medial roots such as gzm 'cut' geminate the medial consonant. The behavior of $b z g$-like and rkz-like verbs in the imperfective is ascribed to the fact that they lack the appropriate structure.

As a direct consequence of the structure proposed, the role of the syllable becomes redundant in selecting the geminating consonant in the verb. Gemination as an imperfectivizing mechanism targets the head of the root rather than the onset of the syllable.

\section{Conclusion}

In this paper, it is argued that triconsonantal verbs in Tashlhiyt Berber obey a set of structural and distributional constraints that limit the nature and the position of segments in the root. Then, it is proposed that the root displays a binary-branching head-complement structure, where only two segments are constrained, namely those that stand for the head and the complement. 
Evidence for this hypothesis is provided by the imperfective formation: it is argued that only verbs that contain at least one sonorant in a non-initial position, and hence display a head-complement structure, geminate one consonant in the imperfective, and that the segment which geminates is that segment which is the head of the root. This allows us to account for a number of forms that are traditionally ascribed to lexical idiosyncrasy, including verbs that are made entirely of obstruents and those where the only sonorant is in the initial position.

\section{Appendix: Data}

This appendix lists 222 verbal roots. They are sorted into 12 classes depending on the kind and the number of consonants they contain. Attention is drawn to the distribution of sonorants and obstruents in the root ( $\mathrm{S}$ stands for a sonorant and $\mathrm{O}$ stands for an obstruent). Each root is assigned a binarybranching head complement structure, built upon the most sonorant segment and the segment immediately to its left (for convenience, the head segment is underlined). The imperfective formation is presented as evidence for this structure. The segment which geminates in the imperfective is that segment which appears in the head position.

In the first class of roots (OOOS), the underlined obstruent is the head and the following sonorant its complement. These roots form their imperfective by geminating the head segment, namely the obstruent immediately on the left of the sonorant.

\section{OQOS}

\begin{tabular}{|c|c|c|}
\hline$\sqrt{ }$ & Imperfective & \\
\hline $\mathrm{bdr}$ & bddr & 'mention' \\
\hline $\mathrm{dr}$ & bddr & 'mention' \\
\hline $\mathrm{du}$ & bddu & 'start' \\
\hline$b d^{\oint} u$ & $\operatorname{bdd}^{\mathrm{f}} \mathrm{u}$ & 'divide' \\
\hline bgu & bggu & 'pierce' \\
\hline bsi & bssi & 'melt, dissolve' \\
\hline $\mathrm{s}$ & bssr & 'spread' \\
\hline$x 1$ & bxxl & 'be stingy' \\
\hline $\mathbf{Z 1}$ & bzzr & 'pluck (feathers)' \\
\hline$d^{i} f r$ & $d^{\mathrm{S}} \mathrm{ffr}$ & 'follow' \\
\hline hi & dhhi & 'push' \\
\hline & fssi & 'melt, dissolve' \\
\hline & fssr & 'spread' \\
\hline & fssu & 'vegetate' \\
\hline & $\mathrm{fttl}$ & 'roll' \\
\hline
\end{tabular}




\begin{tabular}{|c|c|c|}
\hline $\mathrm{ftu}$ & fttu & 'walk, go' \\
\hline gzi & gzzi & 'vaccinate' \\
\hline gzm & gzzm & 'cut' \\
\hline gzr & gzzr & 'slaughter (animal)' \\
\hline $3 \mathrm{dr}$ & $3 \mathrm{ddr}$ & 'burn' \\
\hline $\mathrm{k} \int \mathrm{m}$ & $\mathrm{k} \iint \mathrm{m}$ & 'enter' \\
\hline $\mathrm{k}^{\mathrm{w}} \mathrm{ti}$ & $\mathrm{k}^{\mathrm{w}} \mathrm{tti}$ & 'remember' \\
\hline $\mathrm{kbu}$ & $\mathrm{kbbu}$ & 'pierce' \\
\hline $\mathrm{kd}^{\mathrm{i}} \mathrm{u}$ & $\operatorname{kdd}^{\complement} \mathrm{u}$ & 'smell' \\
\hline kti & $\mathrm{ktti}$ & 'blaze up' \\
\hline sdl & sdal & 'cocoon, sit on' \\
\hline sdu & sddu & 'be side by side with something' \\
\hline $\mathrm{skr}$ & skar & 'do' \\
\hline sti & stay & 'choose' \\
\hline stl & stal & 'weight' \\
\hline syi & syay & 'oblige' \\
\hline syl & syal & 'measure' \\
\hline $\mathrm{s}^{\S} \mathrm{dr}$ & $s^{\complement}$ dar & 'lay' \\
\hline $\mathrm{xsi}$ & xssi & 'be extinct' \\
\hline $\mathrm{xsr}$ & xssr & 'be damaged' \\
\hline $\mathrm{xtl}$ & $\mathrm{xttl}$ & 'feint' \\
\hline xzr & xzzr & 'look nastily' \\
\hline zbi & zbbi & 'hasten' \\
\hline zdi & zday & ‘join’ \\
\hline $\mathrm{zdm}$ & zddm & 'gather firewood' \\
\hline $\mathrm{zdr}$ & zddr & 'lower' \\
\hline $\mathrm{zgr}$ & zggr & 'go across' \\
\hline $\mathrm{zhr}$ & zhhr & ‘blaze up’ \\
\hline$z^{\complement} b r$ & $z^{\complement} \mathrm{bbr}$ & 'prune' \\
\hline$\gamma^{\mathrm{w}} \mathrm{bn}$ & $\mathrm{y}^{\mathrm{w}} \mathrm{bbn}$ & 'lash' \\
\hline$\hbar \int \mathrm{u}$ & $\hbar \iint u$ & 'stick, shove' \\
\hline Ђbu & $\hbar b b u$ & 'hide' \\
\hline$\hbar s r^{\mathrm{f}}$ & $\hbar s s r^{\complement}$ & 'stop' \\
\hline ћsu & hssu & 'learn' \\
\hline
\end{tabular}

Root of the form OSO assign the head and complement function to the first two segments. Their imperfective is formed by means of gemination: they all geminate the first consonant that is in the head position. 


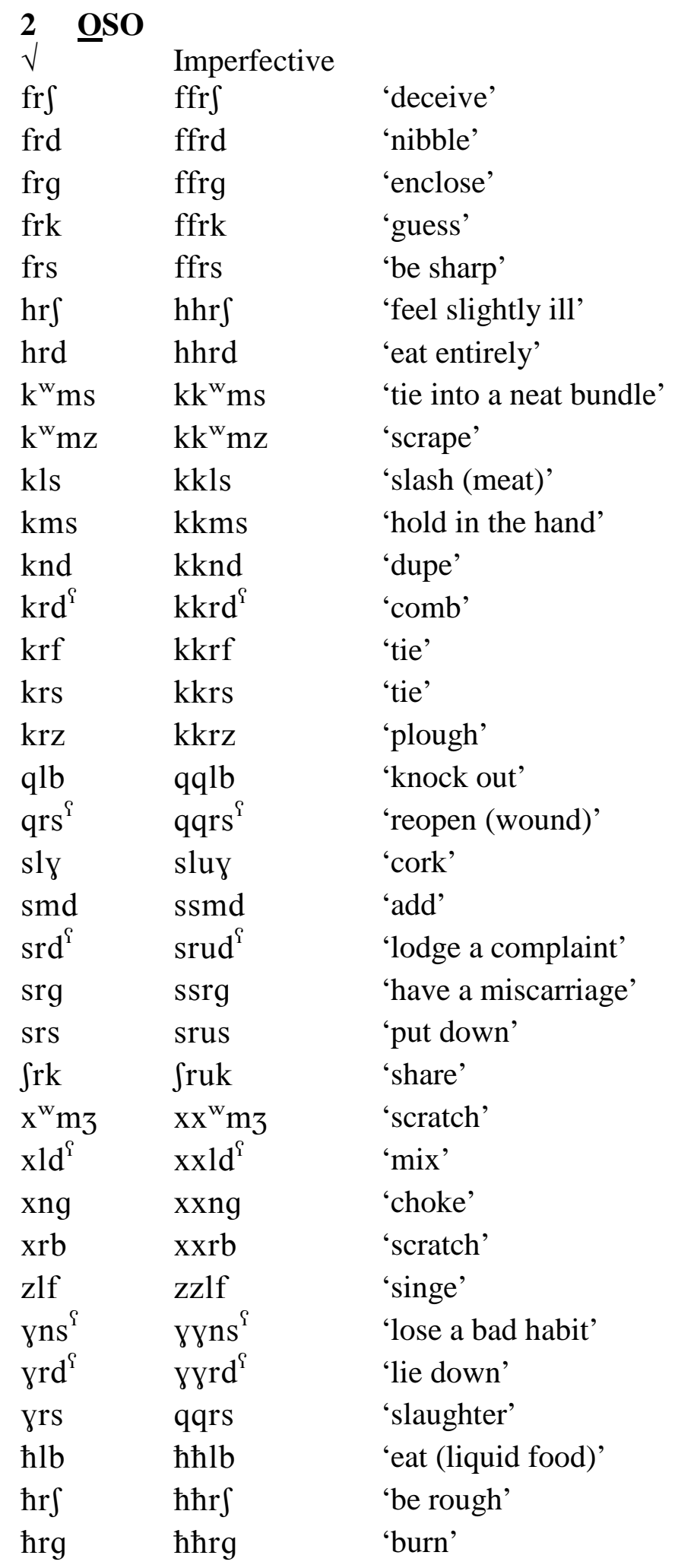


Roots that begin with a sonorant and end with a sonorant are also subject to the head-complement analysis. Their imperfective is obtained by geminating the medial consonant, which is in the head position.

\begin{tabular}{|c|c|c|}
\hline$\sqrt{ }$ & Imperfective & \\
\hline ldi & lddi & 'pull' \\
\hline $\operatorname{lgr}$ & $\operatorname{lggr}$ & 'knock' \\
\hline $\mathrm{km}$ & $1 \mathrm{kkm}$ & 'arrive' \\
\hline mdi & mddi & 'trap' \\
\hline mdu & mddu & 'loose weight' \\
\hline$m d^{\mathrm{S}} \mathrm{i}$ & $\operatorname{mdd}^{\mathrm{i}} \mathrm{i}$ & 'taste' \\
\hline $\mathrm{md}^{\mathrm{g}} 1$ & $\mathrm{mtt}^{\mathrm{f}} 1$ & ‘bury’ \\
\hline mgr & mggr & 'harvest' \\
\hline msi & mssi & 'be tepid' \\
\hline nsl & mssl & 'plug' \\
\hline mzi & mzzi & 'mill, grind' \\
\hline n3m & $\mathrm{n} 33 \mathrm{~m}$ & 'remain unharmed' \\
\hline ndr & nddr & 'suffer' \\
\hline $\mathrm{ndu}$ & nddu & 'strain' \\
\hline $\operatorname{nd}^{\mathrm{i}} \mathrm{r}$ & $n \mathrm{nt}^{\mathrm{f}} \mathrm{r}$ & 'jump' \\
\hline $\operatorname{nd}^{\complement} \mathrm{u}$ & $n \operatorname{tt}^{\mathrm{f}} \mathrm{u}$ & 'jump' \\
\hline nfi & nffi & 'jostle, shove' \\
\hline $\mathrm{hfr}$ & nffr & 'blow one's nose' \\
\hline ngi & nggi & 'flow' \\
\hline ngi & nggi & 'pour' \\
\hline $\mathrm{kr}$ & nkkr & 'stand up' \\
\hline $\mathrm{isr}$ & nssr & 'graze' \\
\hline atl & nttl & 'take shelter' \\
\hline $\mathrm{azl}$ & nzzl & 'prick' \\
\hline $\mathrm{bu}$ & rbbu & 'carry to the back' \\
\hline $\mathrm{rdm}$ & rddm & 'demolish' \\
\hline $\operatorname{rd}^{\mathrm{i}} 1$ & $\mathrm{rtt}^{\mathrm{f}} 1$ & 'borrow' \\
\hline$g l$ & rggl & 'knock' \\
\hline $\mathrm{gmm}$ & rggm & 'insult' \\
\hline rkm & rkkm & 'rot' \\
\hline rku & rkku & 'be dirty' \\
\hline vi & rwwi & 'soil' \\
\hline $\mathrm{zu}$ & $\mathrm{rzzu}$ & 'crawl' \\
\hline
\end{tabular}




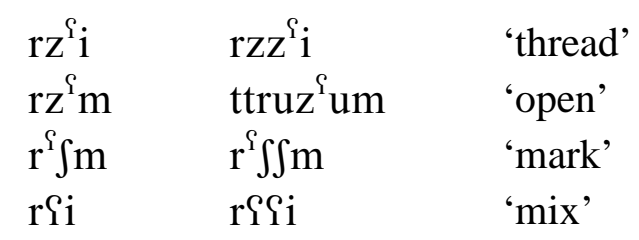

The roots in class 4 all show a binary-branching structure where the medial sonorant is the head and the following sonorant the complement. In the imperfective, they geminate the medial sonorant. The forms that begin with a sibilant behave as causative forms in the imperfective, using vowel insertion rather than gemination.

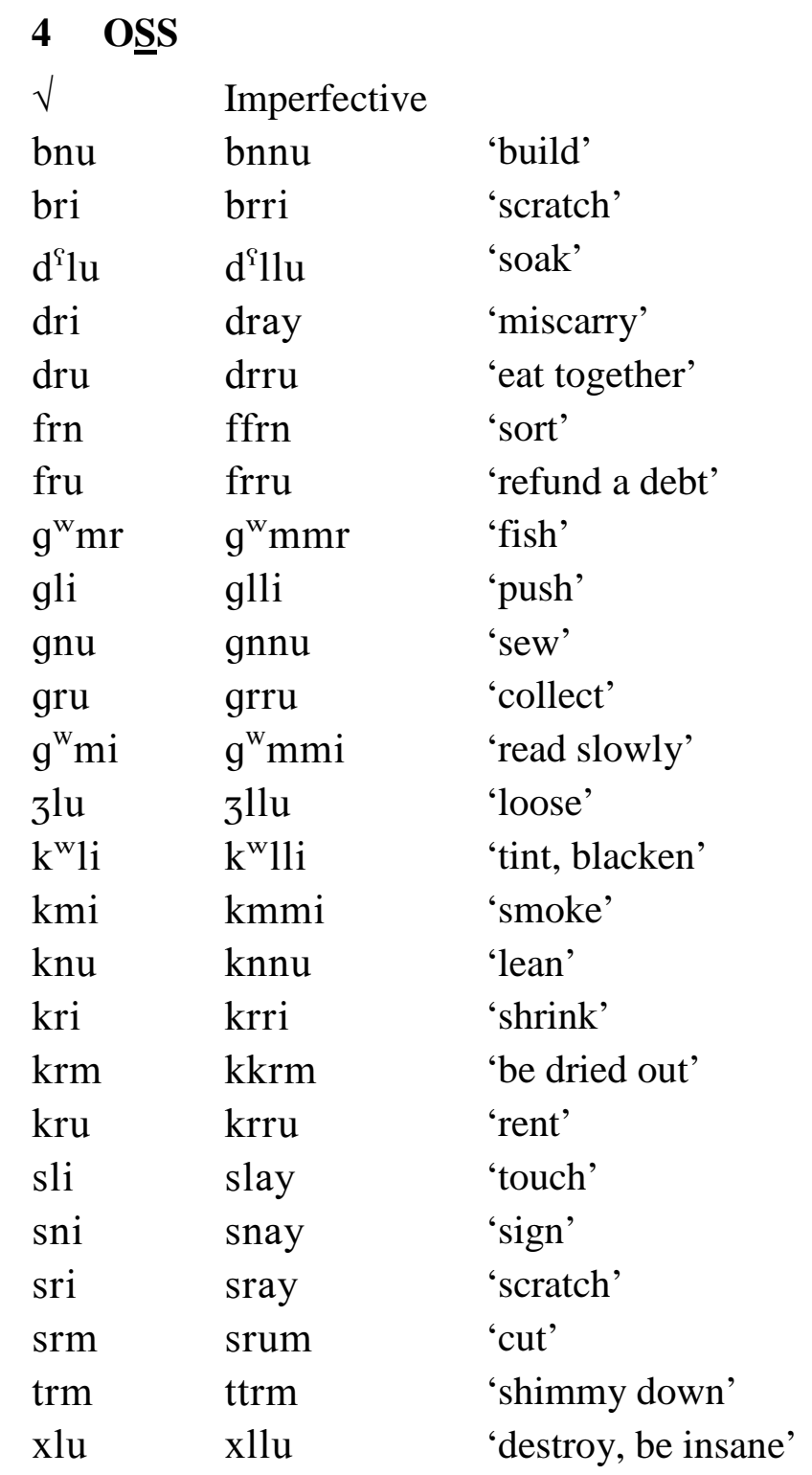




\begin{tabular}{|c|c|c|}
\hline $\mathrm{xmr}$ & $\mathrm{xmmr}$ & 'ferment' \\
\hline$z^{\complement} l i$ & $z^{\text {\& }}$ lay & 'put aside' \\
\hline $\mathrm{zlm}$ & zlum & 'glance' \\
\hline zri & zray & 'pass, go' \\
\hline zru & zrru & 'flea, delouse' \\
\hline zwu & zwwu & 'dry' \\
\hline$z^{\complement} \operatorname{lm}$ & $\mathrm{zz}^{\complement} 1 \mathrm{~m}$ & 'peel' \\
\hline$z^{\complement} w i$ & $z^{\complement} w w i$ & 'left-handed' \\
\hline ylu & yllu & 'be expensive' \\
\hline $\mathrm{yml}$ & ymml & 'mould' \\
\hline ymu & ymmu & 'dyed' \\
\hline$\gamma^{\mathrm{w}} l i$ & aqq"lay & 'go up, climb' \\
\hline hml & hmml & 'enjoy’ \\
\hline hri & hrri & 'be toughless' \\
\hline hrm & ћћrm & 'ignore' \\
\hline
\end{tabular}

Very few roots in Tashlhiyt Berber are of the form SSO. Only four roots are listed in class 5 , three of which form their imperfective by means of affixation. The first two roots have their initial sonorant in the head position, while the remaining resist the head-complement structure, as their most sonorant segment is in the initial position.

$\begin{array}{lll}\mathbf{5} \text { SSO } & & \\ \sqrt{ } & \text { Imperfective } & \\ \operatorname{lmd} & \text { ttlmad } & \text { 'learn' } \\ \operatorname{lmz}{ }^{\complement} & \operatorname{ttlmaz}^{\mathrm{f}} & \text { 'swallow without chewing' } \\ \mathrm{mrg} & \mathrm{ttmrag} & \text { 'be ashamed' } \\ \mathrm{mrz} & \mathrm{mmrz} & \text { 'wound in the head' }\end{array}$

The roots listed in class 6 are not analyzable in terms of head and complement structure, since the only sonorant they contain is in the initial position. Apart from $1 b z^{\varepsilon}$ and $n s d^{f}$, they all use affixation rather than gemination.

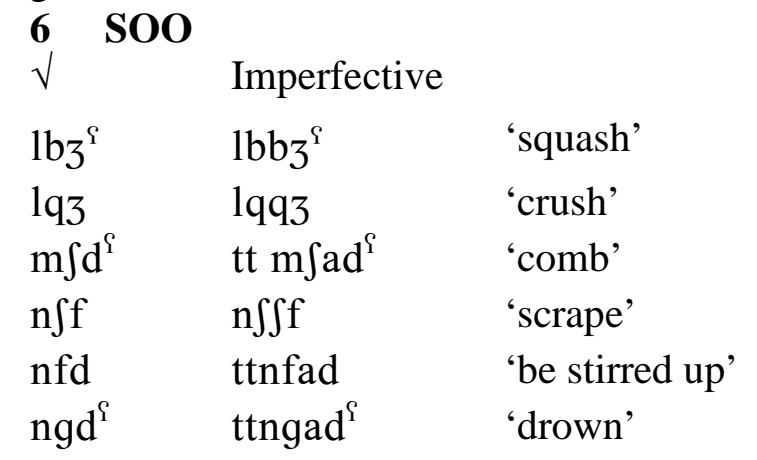




\begin{tabular}{|c|c|c|}
\hline ngs & ttngas & 'jostle, shove' \\
\hline $\mathrm{nsd}^{\mathrm{S}}$ & $\mathrm{nssd}^{\mathrm{S}}$ & 'gush' \\
\hline nyd & ttnyad & 'refine' \\
\hline $\mathrm{ny}^{\mathrm{w}} \mathrm{z}$ & tt $n \gamma^{\mathrm{w}} \mathrm{az}$ & 'blink eye' \\
\hline $\mathrm{rk}^{\mathrm{w}} \mathrm{s}$ & $\operatorname{ttrk}^{\mathrm{w}}$ as & 'hide' \\
\hline rkz & ttrkaz & 'dance' \\
\hline qs & ttrqas & 'jump' \\
\hline
\end{tabular}

Roots that are entirely made of sonorants assign the head to the segment that immediately precedes the most sonorant segment. Their imperfective is formed by means of gemination.

$\begin{array}{lll}\mathbf{7} \text { SSS } & & \\ \sqrt{ } & \text { Imperfective } & \\ \text { lwi } & \text { lwwi } & \text { 'be relaxed, soft' } \\ \text { mlu } & \text { ttmlu } & \text { 'be limp, flabby' } \\ \text { nru } & \text { nrru } & \text { 'defeat' } \\ \text { rmi } & \text { rmmi } & \text { 'be tired' } \\ \text { rwi } & \text { rwwi } & \text { 'make dirty, mix' } \\ \text { rwl } & \text { rwwl } & \text { 'run away' } \\ r^{\text {i }} \text { wu } & \mathrm{r}^{\text {i } w w u ~} & \text { 'remedy' }\end{array}$

Class 8 lists roots that are entirely composed of obstruents. They are not analyzable into a head-complement structure, and hence undergo affixation rather than gemination in the imperfective.

\section{0}

$\sqrt{ } \quad$ Imperfective

bdg ttbdag 'be wet'

bks/biks ttbikkis 'fasten'

bxs ttbxas 'discredit oneself'

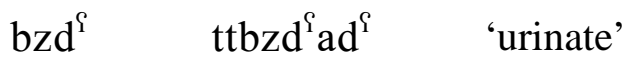

bzg ttbzag 'swell'

dff ttdfas 'punch'

3bd 3bud 'pull'

$\mathrm{k}^{\mathrm{w}}$ fs $\quad$ tt $\mathrm{k}^{\mathrm{w}}$ fas 'sow'

sty stty 'split'

zdg ttzdag 'purify'

zdy ttzday 'inhabit'

The forms listed in 9 are analyzed as being underlyingly trisegmental of the form CCU. As such, they assign the head function to the obstruent, which they all geminate in the imperfective. 


\section{S $\underline{\mathbf{O}}$}

$\begin{array}{lll}\sqrt{ } & \text { Imperfective } & \\ \text { ls } & \text { lssa } & \text { 'wear' } \\ \text { ns } & \text { nssa } & \text { 'overnight' } \\ \text { nz } & \text { nzza } & \text { 'be sold' } \\ \text { ny } & \text { nqqa } & \text { 'kill' } \\ \text { rz } & \text { rzza } & \text { 'break' } \\ \text { ry } & \text { rqqa } & \text { 'be lightened, hot' }\end{array}$

The biconsonantal roots in 10 assign the head to the obstruent, which geminates in the imperfective.

\section{$10 \underline{\mathrm{OS}}$}

\begin{tabular}{|c|c|c|}
\hline$\sqrt{ }$ & Imperfective & \\
\hline $\mathrm{dl}$ & dllu & 'cover' \\
\hline$d^{\complement} \mathrm{i}$ & $\mathrm{tt}^{\mathrm{f}}$ ay & 'drive out' \\
\hline$d^{\complement} r$ & $\mathrm{tt}^{\mathrm{f}} \mathrm{ar}$ & 'fall down' \\
\hline fi & ttfay & 'suppurate' \\
\hline fl & ffal & 'leave' \\
\hline$g 1$ & ggal & 'bust' \\
\hline gn & ggan & 'sleep’ \\
\hline $\mathrm{kl}$ & klla & 'spend a day' \\
\hline su & ssa & 'drink’ \\
\hline . & zwwa & 'be dried' \\
\hline $\mathrm{m}$ & $\mathrm{z}^{\mathrm{i}} \mathrm{mma}$ & ‘wring' \\
\hline$z^{i} r$ & $z^{\oint}$ rra & 'see' \\
\hline$\gamma^{w}{ }_{i}$ & $\mathrm{qq}^{\mathrm{w}} \mathrm{ay}$ & 'catch' \\
\hline
\end{tabular}

The remaining biconsonantals in classes 11 and 12 behave completely paradoxically in their morphological properties, making difficult the decision of wether they are underlying bi- or trisegmental (see pages 19 and 20).

\section{SS}

$\begin{array}{lll}\sqrt{ } & \text { Imperfective } & \\ \mathrm{ml} & \text { mmal } & \text { 'show' } \\ \mathrm{nu} & \text { nwwa } & \text { 'be cooked' }\end{array}$

\section{0}

\section{$\sqrt{ } \quad$ Imperfective}




$\begin{array}{lll}\mathrm{fk} & \text { akka } & \text { 'give' } \\ \mathrm{ks} & \mathrm{kssa} & \text { 'graze' } \\ \mathrm{s \gamma} & \mathrm{ssa \gamma} & \text { 'buy' } \\ \mathrm{zd}^{\text {§ }} & \text { zzad }^{\text {}} & \text { 'mill, grind' } \\ \mathrm{\gamma z} & \text { qqaz } & \text { 'hollow' }\end{array}$

\section{References}

Achab, Ramdane. 1996. La néologie lexicale berbère (1945-1995). ParisLeuven: Peeters.

Anderson, John. 1985. Structural analogy and dependency phonology. Acta Linguistica Hafniensia 19: 5-44.

Anderson, John. 2002. A notational theory of syntactic categories. Cambridge Studies in Linguistics 82. Cambridge: Cambridge University Press.

Anderson, John, and Colin Ewen. 1987. Principles of dependency phonology. Cambridge: Cambridge University Press.

Aronoff, Mark. 1976. Word Formation in Generative Grammar. Cambridge, MA: MIT Press.

Aronoff, Mark, and Frank Anshen. 2001. Morphology and the lexicon: lexicalization and productivity. In The Handbook of Morphology, ed. by Andrew Spencer and Arnold Zwicky, 237-247. Oxford: Blackwell Publishers.

Bagemihl, Bruce. 1991. Syllable structure in Bella Coola. Linguistic Inquiry 22: 589-646.

Basset, André. 1929. La langue berbère: morphologie, le verbe, étude de thèmes. Paris: L'Harmattan, (edition 2004).

Bat-El, Outi. 1994. Stem modification and cluster transfer in Modern Hebrew. Natural Language and Linguistics Theory 12: 571-596.

Bat-El, Outi. 2003. The fate of the consonantal root and the binyan in Optimality Theory. Recherches Linguistiques de Vincennes 32: 31-60.

Bauer, Laurie. 2001. Morphological productivity. Cambridge: Cambridge University Press.

Bensoukas, Karim. 2001. Stem forms in the nontemplatic morphology of Berber. Doctoral dissertation, Université Mohammed 5, Rabat.

Boukous, Ahmed. 1987. Phonotactique et domaines prosodiques en berbère. Doctoral dissertation, Université Paris 8.

Boumalk, Abdallah. 2003. Manuel de conjugaison du tachelhit (langue berbère du Maroc). Paris: L'Harmattan.

Cadi, Kadour. 1987. Système verbal rifain, forme et sens. Paris: Selaf.

Cantineau, Jean. 1950. Racines et schèmes. In Mélanges offerts à William Marçais, 119-124. Paris: A. Maisonneuve. 
Chaker, Salem. 1973. Le système dérivationnel verbal berbère (dialecte Kabyle). Doctoral dissertation, Université Paris 3.

Chaker, Salem. 1984. Système des oppositions verbales (kabyle), formes et valeurs. Textes en linguistique berbère: introduction au domaine berbère, 160-176. Paris: CNRS Editions.

Chaker, Salem. 1990. Les bases de l'apparentement chamito-sémitique du berbère : un faisceau d'indices convergents. Etudes et documents berbères 7: 28-57.

Chami, Mohamed. 1979. Un parler amazighe du Rif marocain. Doctoral dissertation, Université Paris 5.

Clements, George N. 1990. The role of the sonority cycle in core syllabification. In Papers in Laboratory Phonology 1: Between the grammar and physics of speech, ed. by John Kingston and Mary Beckman, 283-333. Cambridge: Cambridge University Press.

Cohen, David. 1972. Problèmes de linguistique chamito-sémitique. Revue des Etudes Islamiques 40: 43-68.

Cohen, David. 1988. Les langues dans le monde ancien et moderne: langues chamito-sémitiques. In Langues dans le monde ancien et moderne, vol. III, ed. by Daniel Cohen and Jean Perrot, 9-30. Paris: CNRS Editions.

Cohen, Marcel. 1947. Essais comparatif sur le vocabulaire et la phonétique du chamito-sémitique. Paris: Champion.

Dell, François, and Mohamed Elmedlaoui. 1985. Syllabic consonants and syllabification in Imdlawn Tashlhiyt Berber. Journal of African Languages and Linguistics 7: 1-17.

Dell, François, and Mohamed Elmedlaoui. 1988. Syllabic consonants in Berber: some new evidence. Journal of African Languages and Linguistics 10: 1-17.

Dell, François, and Mohamed Elmedlaoui. 1991. Clitic ordering, morphology and phonology in the verbal complex of Imdlawn Tashelhiyt Berber. Langues Orientales Anciennes Philologie et Linguistique 3: 77-104.

Dell, François, and Mohamed Elmedlaoui. 1992. Quantitative transfer in the nonconcatenative morphology of Imdlawn Tashlhiyt Berber. Journal of Afroasiatic Languages 3: 89-125.

Dell, François, and Mohamed Elmedlaoui. 2002. Syllables in Tashlhiyt Berber and in Moroccan Arabic. Dordrecht: Kluwer Academic Publishers.

Dell, François, and Ahmed Jebbour. 1991. Phonotactique des noms à voyelle initiale en berbère (chleuh de Tiznit, Maroc). Linguistic Analysis 21: 119-147.

Diakonoff, Igor Mikhailovich. 1970. Problems of root structure in ProtoSemitic. Archiv Orientalni 38: 453-80. 
Diakonoff, Igor Mikhailovich. 1988. Semitico-Hamitic languages, Afrasian languages. Moscow: Nauka.

Dresher, Elan. 1999. Child phonology, learnability, and phonological theory. In Handbook of Language Acquisition, ed. by Tej Bhatia and William C. Ritchie, 299-346. New York: Academic Press.

Elmedlaoui, Mohamed. 1994. Extension de la racine chamito-sémitique. Linguistique Africaine 12: 93-118.

El Mountassir, Abdallah. 2003. Dictionnaire des verbes tachelhit-français (parler berbère du sud du Maroc). Paris: L'Harmattan.

Galand, Lionel. 1988. Le berbère. In Langues dans le monde ancien et moderne, vol. III, ed. by Daniel Cohen and Jean Perrot, 207-242. Paris: Editions CNRS.

Greenberg, Joseph. 1955. Studies in African linguistic classification. New Haven: Compass Publishing Company.

Hammond, Michael. 1984. Constraining metrical theory: a modular theory of rhythm and destressing. Doctoral dissertation, UCLA, Los Angeles.

Hammond, Michael. 1988. Templatic transfer in Arabic broken plurals. Natural Language and Linguistic Theory 6: 247-270.

Hockett, Charles. 1954. Two models of grammatical description. Word 10: 210-234.

Ibn Jinni, Uthman Abu al-Fath. d. 1002. Sirr sinaa'at al i'raab. Beirut: Dar Al-Koutoub Al-Ilmiya, (edition 2000).

Iazzi, Elmehdi. 1991. Morphologie du verbe en tamazight (parler des Aït Attab, Haut Atlas Central): approche prosodique. D.E.S dissertation, Université Mohammed 5, Rabat.

Idrissi, Ali. 2001. Towards a root-and-template approach to shape-invariant morphology. Doctoral dissertation, UQAM, Montreal.

Idrissi, Ali, Jean-François Prunet, and Renée Béland. 2008. On the mental representation of Arabic roots. Linguistic Inquiry 39: 221-259.

Jebbour, Abdelkrim. 1996. Morphologie et contraintes prosodiques en berbère (tachelhit de Tiznit): analyse linguistique et traitement automatique. Doctoral dissertation, Université Mohammed 5, Rabat.

Jebbour, Abdelkrim. 1999. Syllable weight and syllable nuclei in Tashlhiyt Berber of Tiznit. Cahiers de Grammaire 24: 95-116.

Kaye, Jonathan, Jean Lowenstamm, and Roger Vergnaud. 1985. The internal structure of phonological elements: a theory of charm and government. Phonology Yearbook 2: 305-328.

Kaye, Jonathan, Jean Lowenstamm, and Roger Vergnaud. 1990. Constituent structure and government in phonology. Phonology Yearbook 7: 193231.

Kayne, Richard. 1994. The antisymmetry of syntax. Cambridge, MA: MIT Press.

Kossmann, Maarten. 1997. Grammaire du parler berbère de Figuig. ParisLeuven: Peeters. 
Lahrouchi, Mohamed. 2001. Aspects morpho-phonologiques de la dérivation verbale en berbère (parler chleuh d'Agadir). Doctoral dissertation, Université Paris 7.

Lahrouchi, Mohamed. 2004. Gémination, réduplication et gabarits dans un langage secret du berbère tachelhit. In Proceedings JEL'2004 Domaines, ed. by Olivier Crouzet, Hamida Demirdache, and Sophie Wauquier, 07-12. Nantes: Université de Nantes.

Levin, Juliette. 1985. A metrical theory of syllabicity. Doctoral dissertation, MIT, Cambridge, MA.

Louali, Naïma, and Gérard Philippson. 2004. Le thème de l'aoriste intensif: formes multiples, contenu unique. In Nouvelles Etudes Berbères, Le Verbe et autres Articles, ed. by Kamal Naït-Zerrad, Rainer Vossen, and Dymitr Ibriszimow, 79-94. Frankfort: Rüdiger Köppe Verlag.

McCarthy, John. 1979. Formal problems in Semitic phonology and morphology. Doctoral dissertation, MIT, Cambridge, MA.

McCarthy, John. 1981. A prosodic theory of nonconcatenative morphology. Linguistic Inquiry 12: 373-418.

McCarthy, John. 1991. L'infixation réduplicative dans les langages secrets. Langages 101: 11-29.

McCarthy, John, and Alan Prince. 1990. Foot and word in prosodic morphology: the Arabic broken plurals. Natural Language and Linguistic Theory 8: 209-283.

Moktadir, Khalid. 1989. The passive form in Tashlhiyt Berber: a prosodic approach. D.E.S. dissertation, Université Mohammed 5, Rabat.

Moscati, Sabatino et al. 1964. An introduction to the comparative grammar of the Semitic languages. Wiesbaden: Harrassowitz Verlag.

Pater, Joe. 2002. Form and substance in phonological development. In Proceedings of WCCFL 21, ed. by Line Mikkelson and Christopher Potts, 348-372. Somerville, MA: Cascadilla Press.

Prince, Alan. 1985. Improving tree theory. In Proceedings of Berkeley Linguistic Society 11, ed. by Mary Niepokuj, Mary VanClay, Vassiliki Nikiforidou, and Deborah Jeder, 471-490. Berkeley: BLS, University of California.

Prunet, Jean-François. 2006. External evidence and the Semitic root. Morphology 16: 41-67.

Prunet, Jean-François, Renée Béland, and Ali Idrissi. 2000. The mental representation of Semitic words. Linguistic Inquiry 31: 609-648.

Ratcliffe, Robert. 1997. Prosodic templates in a word-based morphological analysis of Arabic. In Perspectives on Arabic Linguistics X, ed. by Mushira Eid and Robert Ratcliffe, 147-171. Amsterdam/philadelhia: John Benjamins.

Rose, Yvan. 2000. Headedness and prosodic licensing in the L1 acqusition of phonology. Doctoral dissertation, McGill University, Montréal. 
Sagarna, Andoni. 1988. Algunos aspectos de la modernizaciôn del léxico en varias lenguas. Doctoral dissertation, Universitat Autônoma de Barcelona.

Spencer, Andrew. 1991. Morphological Theory. Oxford: Blackwell.

Taïfi, Miloud. 1997. Le lexique berbère: entre l'emprunt massif et la néologie sauvage. International Journal of Sociology of Language 123: 61-80.

Tobin, Yishai. 1990. A combinatory phonology of the Hebrew triconsonantal (CCC) root system. La linguistique 26: 99-114.

Ussishkin, Adam. 1999. The inadequacy of the consonantal root: Modern Hebrew denominal verbs and output-output correspondence. Phonology 16: 401-442.

Weil, Gérard. 1979. Trilitéralité fonctionnelle ou bilitéralité fondamentale des racines verbales hébraïques, un essai d'analyse quantifiée. Revue d'Histoire et de Philosophie Religieuses 59: 281-311.

Zaborski, Andrzej. 1991. Biconsonantal roots and triconsonantal root variation in Semitic: solutions and prospects. In Semitic Studies in Honor of Wolf Leslau on the Occasion of his 85th Birthday 2.1, ed. by Wolf Leslau and Alan S. Kaye, 675-703. Wiesbaden: Harrassowitz Verlag.

CNRS - Université Paris 8

UMR 7023 - Structure Formelle du Langage

2 rue de la Liberté

93526 Saint-Denis Cedex France

mlahrouchi@univ-paris8.fr

I am grateful to many people for discussion, comments and criticisms: Jean

Lowenstamm, Bridget Copley, Ali Idrissi, Tobias Scheer, and Jean-François

Bourdin, as well as the audience at the Thirtieth Annual Colloquium of Generative Linguistics in the Old World. I am also grateful to the editors and the anonymous reviewers for their valuable feedback. All remaining errors or omissions are of course my own.

${ }^{1}$ In the sense of "lexical items". 
2 See among others M. Cohen (1947: 58), D. Cohen (1972, 1988), and Chaker (1990).

${ }^{3} / l, r, n, m, b, f /$. Most of them are sonorants. The labials $/ f, b /$ probably result form a well known phonetic change in Semitic by means of which $m$ $\rightarrow b \rightarrow f / p$ (see Moscati et al.1964: 24).

${ }^{4} 17$ roots out of 222 listed in the appendix are made entirely of obstruents. They are discussed in section 3.5.

5 This is called a "cranberry" morpheme in reference to cran-, which is a kind of bound morpheme that cannot be assigned a specific meaning nor does it function as an independent word (see Aronoff 1976, and Spencer 1991).

${ }^{6}$ In Semitic morphology, roots relate to patterns. This is called root-andpattern morphology (see McCarthy 1979, 1981, and subsequent works).

${ }^{7}$ For alternative views to root-based approaches to Semitic morphology, see among others Bat-EL (1994), Ratcliffe (1997), and Ussishkin (1999).

${ }^{8}$ Alternative works in the same tradition argue that roots in Berber are consonantal as much as in Semitic (see Idrissi 2001: 125-176, and Lahrouchi 2004).

9 We should note, however, that such formations involve different operations that refer to the traditional distinction in morphological theory between morpheme-based (Item-and-Arrangement) and word-based (Itemand-Process, and word-and-paradigm) models (see Hockett 1954). The 
association of consonantal roots to templates belongs to the first type of morphology, while vocalic alternations belong to the second type. In a number of criticisms of morpheme-based models, attention is drawn on their failure to account for the problem of melodic transfer found in certain derivations. For example, in the verb-noun derivation $b b z$ 'to punch' / ubbiz 'a punch' gzzr 'cut up' / agzzar 'butcher' in Berber, the geminated consonant in the verb form also appears in the noun form. According to Dell and Elmedlaoui (2002: 55), root-based analyses do not explain why the 'derived forms preserve as much as possible the length of the consonants in the source words". On the other hand, word-based models face the problem of arbitrariness of the input. Thus, for instance, the decision as to which of the singular asaru 'pipe' or plural isura is the input to derivation is fairly arbitrary, since the vocalic alternation they display is not sufficient to determine the direction of derivation.

10 The notion of "productivity" in morphology is still under debate. Some authors discuss affix productivity; others talk about productive processes or rules (see Bauer 2001: 12, and references therein). Moreover, authors such Aronoff and Anshen (2001: 242) distinguish quantitative and qualitative productivity.

${ }^{11}$ Loanwords, mostly form Arabic, are not examined here. They behave differently from native words. We will return to this issue later in the paper (see section 5.3). 
${ }^{12}$ Tashlhiyt Berber has the following segmental inventory: $\mathrm{t}, \mathrm{t}^{\mathrm{f}}, \mathrm{k}, \mathrm{k}^{\mathrm{w}}, \mathrm{q}, \mathrm{q}^{\mathrm{w}}$, b, d, d $d^{\mathrm{s}}, \mathrm{g}, \mathrm{g}^{\mathrm{w}}, \mathrm{m}, \mathrm{n}, \mathrm{l}, \mathrm{y}, \mathrm{w}, \mathrm{f}, \mathrm{s}, \mathrm{s}^{\mathrm{s}}, \int, \mathrm{x}, \mathrm{x}^{\mathrm{w}}, \mathrm{h}, \mathrm{z}, \mathrm{z}^{\mathrm{f}}, 3, \mathrm{\gamma}, \mathrm{\gamma}^{\mathrm{w}}, \mathrm{\uparrow}, \mathrm{h}, \mathrm{r}, \mathrm{i}, \mathrm{u}, \mathrm{a}$.

${ }^{13}$ Given the large number of obstruents in the language (the segmental inventory in footnote 12 lists 25 obstruents and 8 sonorants), and assuming that there are no constraints on the segmental content of the root, and that every consonant has an equal chance of occurring, we would expect that over half of the CCC roots in the appendix would be of the form OOO, when in fact only 11 are found.

${ }^{14}$ For the purpose of this analysis, I am assuming the following sonority scale, where segments appear in order of increasing sonority: Obstruent > Nasal $>$ Liquid $>$ Glide $>$ Vowel (see Clements 1990).

${ }^{15}$ Cross-linguistic evidence for the structuring role of the obstruent-sonorant pattern is provided by the syllable structure of Bella Coola, a Salish language spoken on the central coast of British Columbia. Bagemihl (1991: 597) analyzes the reduplication in forms such as $t l^{\prime} k^{w}$ 'swallow' $\rightarrow$ tltl' $k$ 'swallow-continuative' and tqnk 'be under $\rightarrow$ tqnqnk 'underwear' as the result of prefixation of a $\mathrm{CV}$ syllable to the word, where the sonorant occupies the V position and where CC clusters are of the form obstruentsonorant.

${ }^{16}$ On the notions of Head and Complement, and the way they are used in phonological theory, the reader is referred to Dependency Phonology 
(Anderson 1985, 2002, Anderson and Ewen 1987), Government Phonology (Kaye, Lowenstamm, and Vergnaud 1985, 1990), and Metrical Phonology (Hammond 1984, Prince 1985). The binary-branching head-complement hypothesis is also reflected in the theory of syllable representation developed by Levin (1985): the syllable is viewed as a projection of the Nucleus (N). The coda is defined as the Complement of $\mathrm{N}$ while the onset is the specifier of the syllable: for example, pin

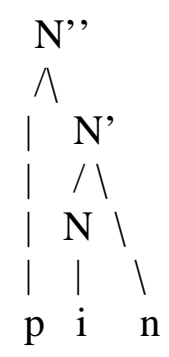

${ }^{17}$ In almost all languages, vowels are the uncontroversial heads, prior to any other segments to occur as nuclei. In certain languages, however, consonants may be syllabic if there were no vowels available in the neighboring segments. Tashlhiyt Berber, English, and certain Slavic languages are of this type.

18 Language acquisition data show a tendency for children to reduce obstruent-sonorant clusters to obstruents: for example English flowers $\rightarrow$ [fauwðr], sleep $\rightarrow$ [sip], frog $\rightarrow$ [fa:g] (see Pater 2002: 353); French $\underline{\text { clé }} \rightarrow$ [ke] 'key', clown $\rightarrow$ [kuj], train $\rightarrow[\mathrm{k} \varepsilon]$ (see Rose 2000: 132). Keeping the 
obstruent in the output can thus be seen as an argument for the role of such a segment in the sound structure of words.

${ }^{19}$ Quadriconsonantal verbs support the binary branching head-complement hypothesis. Most of them are reduplicated biconsonantal roots. Here are some examples: $b r b r$ 'boil ', frfr 'beat with wings ', and $d u r d r$ ' be unable to hear'.

20 Within Syntactic structures, the Linear Correspondence Axiom universally states that all syntactic constituents are left-headed. That is, the head always precedes its complement.

${ }^{21}$ Further evidence for the above assumption lies in learners' ability to make generalizations on the underlying form of words. Regarding the surface form of the verbs in (16a), particularly the fact that they all geminate the medial consonant, and based on cross-linguistic evidence (in Classical Arabic, for instance, the forms kaana 'he/it was', maata 'he died' and daara 'he turned' are analyzed as being underlyingly trisegmental, of the form form $k w n, m w t$ and $d w r$ ), and statistical factors specific to the language (all verbs that end with a vowel in the aorist that vowel is $u$ or $i$ ), we can assume that Tashlhiyt Berber learners analyze them as being underlying trisegmental. 
${ }^{22}$ In the varieties of Tashlhiyt Berber described in Boumalk 2003 and El Mountassir 2003, as well as in my own variety, the verb $3^{b d}$ forms its imperfective as $3 b u d$.

${ }^{23}$ Dell and Elmedlaoui (2002: 76) assume the following sonority scale, where segments are ranked in a decreasing sonority order: $a$, high vocoids, liquids, nasals, fricatives, stops.

${ }^{24}$ Dell and Elmedlaoui (1988: 11) draw up a list of conditions that each verb in Imdlawn Tashlhiyt Berber should satisfy in order to undergo gemination, stating "a. the basic stem contains three segments none of which is a geminate; $b$. if the basic stem contains a vowel, that vowel must be the last segment".

${ }^{25}$ In the footnote $n^{\circ} 22$ page 16, Dell and Elmedlaoui (1988) claim that the verbs $b x s$ 'discredit oneself' and $d f \int$ 'punch', which are actually attested in Imdlawn Tashlhiyt Berber, do not form their imperfective by means of gemination.

${ }^{26}$ See for instance Boumalk (2003), and El Mountassir (2003). 